\title{
Organic Architecture of Japan
}

\author{
Nina Konovalova ${ }^{1, *}$
}

\begin{abstract}
${ }^{1}$ Scientific Research Institute of the Theory and History of Architecture and Urban Planning, branch of the Federal State Budget Institution "Central Scientific-Research and Project Institute of the Construction Ministry of Russia", Moscow, Russia

*Corresponding author. Email: phuekirjuko@mail.ru
\end{abstract}

\begin{abstract}
The main components of organic architecture, leading to the inner harmony of an architectural structure, are archetypal for the architecture of Japan. Since ancient times, those principles have been identified and placed at the head of absolute harmony, which has become the essence of the Japanese culture. Using the example of Japanese architecture, Wright was able to confirm the correctness and solidity of his provisions of organic architecture. For Wright, many of the 'organic' characteristics of his theory have been embodied in traditional Japanese architecture. Creating his works in Japan, Wright found students and followers, having a significant impact on the development of Japanese architecture, which is felt up to this day.
\end{abstract}

\section{Keywords: organic architecture, Frank Lloyd Wright, Imperial Hotel, contemporary architecture of Japan}

\section{INTRODUCTION}

The main components of organic architecture, leading to the inner harmony of an architectural structure, are archetypal for the architecture of Japan, which has identified these principles and placed them at the head of absolute harmony, which has become the essence of Japanese culture since ancient times. Japanese philosophy, and all areas of artistic creation, and, of course, architecture, is imbued with such principles.

Frank Lloyd Wright, the founder and theorist of 'organic architecture' was inspired with the architecture of Japan. It is impossible to say unambiguously that F.L. Wright formulated the provisions of organic architecture, guided only by the leading principles of organizing the space of traditional Japanese architecture. He described a number of forms of traditional Japanese art and architecture as 'organic'. Wright's usage of this term in relation to traditional Japanese architecture was based on its fundamental principles: fair presentation of material, free flow of space, artistic and aesthetic integrity of the object, and environmental friendliness. Those principles, each of which had its own history of existence and development in European architecture, together had a significant impact on Western theory and practice as a direction of organic architecture [1].

For Wright, many of the 'organic' characteristics of

*Fund: This paper was funded by the Program of Fundamental Researches of the Ministry of Construction, Housing and Utilities of the Russian Federation and the Russian Academy of Architecture and Construction Sciences 2020, the Research Project 1.4.1. his theory have been embodied in traditional Japanese architecture. First of all, he pays attention to the fair presentation of material, wood, emphasizing its texture in traditional architecture. Japanese masters refuse unnecessary things, any 'decoration' of architecture; they are "bringing out and polishing the beauty of the simple materials used in making the building" [2]. All Japanese aesthetics are built on this - it is based on the nature of building materials, in this case, wood, showing the beauty of its texture.

Wright also admired how many Japanese buildings were so well adapted to their surroundings that they almost seemed to blend in with the landscape. A building taken out of context, in Wright's opinion, cannot exist. According to Wright, the shape of a building should each time follow from its specific purpose and those unique environmental conditions in which it is erected and exists. The architect believes that harmony with the environment is a necessary concept. It also formed the basis of his 'organic architecture'. Researchers have always noted a close connection between a traditional Japanese house and a garden that surrounds it, the mutual overflow of external and internal spaces [3]. This sense of continuity in the perception of home and garden is undoubtedly one of the most important characteristics that unite Wright's work with traditional Japanese architecture. In this way, an interconnected space is created, which also underlies Wright's concept of 'organic' architecture. Perhaps, more than any other idea, the architecture of Japan has embodied the concept of an interdependent 'organic' environment, where each seemingly separate entity actually depends 
on its neighbors both in meaning and in its very existence [4].

Within the framework of the concept of 'organic architecture', Wright creates his 'prairie houses', the ideal of which is integrity and unity with nature [5]. In this philosophy, the house can be compared to a living organism, in which all parts are connected to the whole, and form and function are completely intertwined. The 'prairie house' style is characterized with an abundance of horizontal lines, a predominance of flat roofs, wide protruding cornices and intricate ornamentation. The horizontal details of those constructions resembled the landscapes of the Great Plains, which explains the figurative name of the style [6]. At the same time, the style was certainly under the influence of the image of Japanese temples. Wright's 'prairie houses' served as a natural extension of the natural environment, much like the evolutionary form of natural organisms. They are characterized with an open plan, horizontals prevailing in the composition, roof slopes far removed from the house wall, terraces, finishing with raw natural materials, rhythmic division of the facade with frames, the prototypes of which were Japanese temples. Many of the houses are cruciform in plan, and the central fireplace combines an open space. Wright paid special attention to the interiors of houses, creating furniture himself and ensuring that each element was meaningful and organically fit into the environment he created.

\section{F.L. WRIGHT' ARCHITECTURE IN JAPAN}

Important sources of inspiration for Wright were his love for nature and his close ties with Japan, where he opened his own architecture office and worked actively. For Japan, Wright designed fourteen buildings [7]. Some of them have been never built, some were later destroyed. Only three have survived to this day.

The most famous of the Wright's works in Japan was the 'Imperial Hotel' in Tokyo ("Fig. 1"). Several times rebuilt ${ }^{1}$, the 'Imperial Hotel' at every stage of its construction, was the personification of a new, progressive Japan. Since its inception, the hotel has become one of the key Japanese buildings in the Western style. One of the stages of necessary expansion of the hotel was to lead to the appearance of a new grandiose building. To work out the project, F.L. Wright was invited; he had already won worldwide recognition by that time. Wright came to Japan in 1913. During his stay in the country, the architect inspected the site and drew some preliminary plans. In 1917, Wright returned to Japan to prepare for construction: to inspect the site more closely, to approve materials, and to hire draftsmen to fulfill technical drawings. In late 1919, when the work on the new hotel had just begun,

\footnotetext{
The 'Imperial Hotel' was opened in Tokyo for the first time in 1890; since then, it was numerously rebuilt.
}

the original building of the 'Imperial Hotel' (built in 1906) was badly damaged in a fire. Work on the new hotel was halted, but during this time Wright designed a temporary building that was reopened five months later.

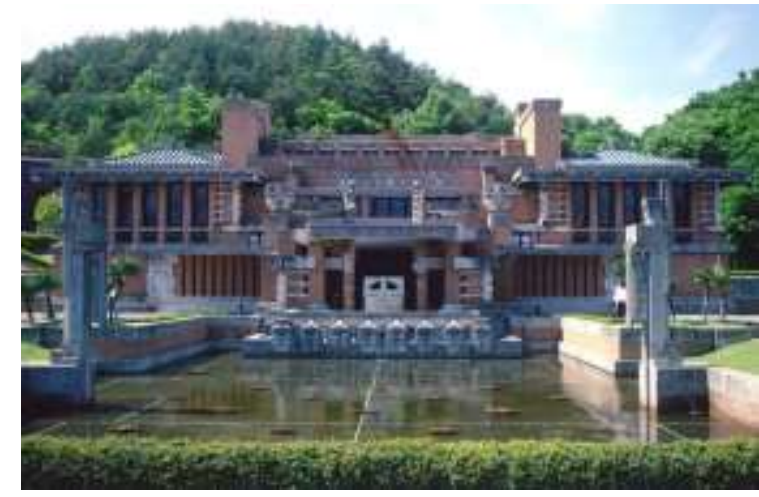

Fig. 1. F.L. Wright. 'Imperial Hotel', Tokyo, 1923.

On April 26, 1922, a massive earthquake struck Tokyo and completely destroyed the original hotel building. [8] The north wing of the new hotel and the partially completed central section were opened on July 2,1922 . Since the south wing was a mirror image of the northern one, Wright decided that he could leave the completion under the supervision of his assistant, architect Arato Endo. Wright left Japan on July 22, 1922 , as it turned out, forever. The hotel took another eleven months to be build and was officially opened in June 1923.

The visual impact of the hotel building was overwhelming to the Japanese of that time. The hotel building was a tall pyramidal structure with a courtyard and pool leading to the multi-tiered main building. Corridors and bridges were used to connect the three main buildings to each other. The interior has been executed with rich ornamentation. The main building materials were concrete blocks and the carved Oya stone. The use of Oya stone immediately refers to the building tradition of Japan. Oya stone is a kind of greenish volcanic tuff, lightweight and durable; it was one of the main building materials of Old Japan ${ }^{2}$.

One of the main design features of the hotel building was its foundation. The powerful 'floating' substructure went 18 meters into the ground. In addition, the hotel had other features that Wright had envisioned to minimize potential damage from an earthquake: seismic separation joints, located approximately every 20 meters along the building; conical walls, which are thicker on the lower floors, which increases their strength; cantilevered floors and

\footnotetext{
2 In medieval Japan, Oya stone was used for fortress walls, road covering, etc. The only deposit of Oya stone in the world is located near the city of Utsunomiya, where old quarries are still can be seen.
} 
balconies provided additional support for the floors; piping and electrical wiring were suspended rather than encased in concrete; The on-site pool also served as a source of water to extinguish fires and to save the building from the effects of an earthquake.

In 1923, the 'Imperial Hotel' experienced a powerful earthquake - the Great Kantō earthquake. The hotel building survived, although it was damaged: the central section fell, several floors were cut; besides, many minor damages were recorded ${ }^{3}$.

The second surviving Wright's building in Japan is the Jiyu Gakuen Girls' School Myonichikan ("Fig. 2"). This is a free school built by Wright in Tokyo in 1921 . Arata Endo, Wright's assistant in the construction of the 'Imperial Hotel', introduced the architect to his acquaintances Yosikazu and Motoko Hani, who founded the Jiyu Gakuen Company. Impressed with the couple's self-sufficient, Christian-centered educational philosophy, Wright was enthusiastic about designing their new school. The school was conceived as a complex of buildings, consisting of four separated parts: main, east, west, as well as the building of the auditorium. The main building was two-storey, flanked with two educational buildings facing west and east, forming the U-shape. High windows of the buildings overlooked the open courtyard. The buildings were distinguished with the length of horizontal lines that help them to fit perfectly into the landscape. Overall, the school's architectural design was reminiscent of the 'prairie architecture' by Wright of his early days.

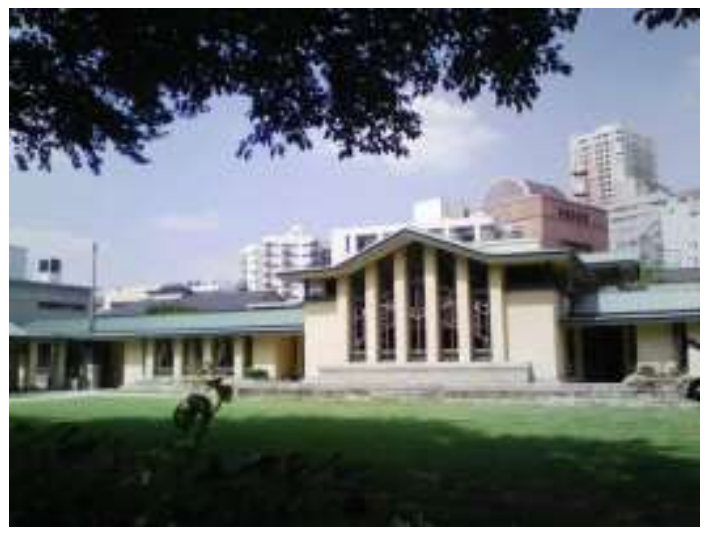

Fig. 2. F.L. Wright. Jiyu Gakuen Girls' School Myonichikan, Tokyo, 1921.

The architect also brought in some Japanese building traditions: the gray-green Oya stone (brought from Totigi Prefecture), beloved by Wright, was widely used. It was used for paving paths and sidewalks, as

The hotel building was also damaged in the WWII. In 1968 the preserved elements of the complex were transferred to the architectural museum Meiji Mura in Aichi Prefecture, where they are kept nowadays. well as for interior decoration - columns and lanterns in the corridors. Wooden window frames got an interesting geometric pattern, which became one of the striking features of the project. Wright designed himself furniture and lighting for the school's interiors. The Jiyu Gakuen Girls' School Myonichikan is one of a few examples of Wright's work in Japan that has completely retained its original appearance ${ }^{4}$

The third work by the famous architect in Japan is the Yodokō Guest House (Tazaemon Yamamura House, "Fig. 3"). It was created in the city of Ashiya, Hyogo Prefecture, as a summer villa for a rich sake and beer producer Tazaemon Yamamura. The residence was designed by Wright as a project in 1918; its construction was completed in 1924. The Yodokō Guest House is an reinforced concrete building, which was a great rarity for Japan of 1920-s.

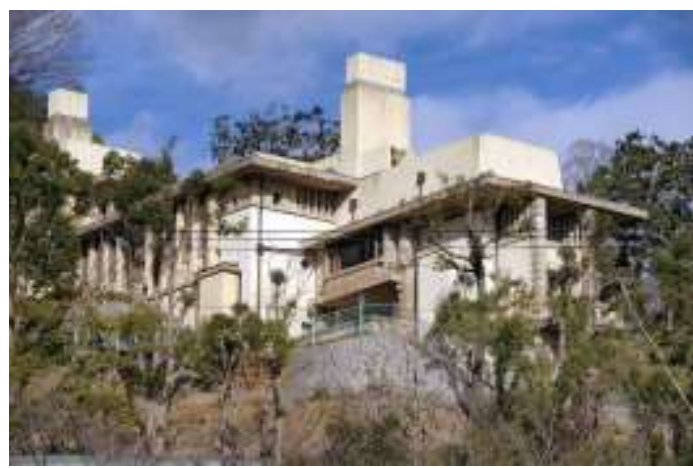

Fig. 3. F.L. Wright. Yodokō Guest House, Ashiya, 1924.

The villa was built on the slope of a hill and fit well into the natural landscape. The architect took into account all the perspectives of such a variant of the location of the building. Panoramic views of the upper floors' large windows of the building and balconies allow to observe all the environment beauty: the Rokko Mountains, the Kobe Port, the Osaka Bay, and the general cityscape. The approach to the villa was carefully thought out by the architect. A long road leads to the house through a picturesque area. At the front entrance there are special areas for relaxation and contemplation of the surroundings. In general, special attention in the project was paid to directing visual panoramas.

The decoration of the Yodokке Guest House, as well as in other Japanese works of Wright, used decorative blocks of Oya stone [9]. The center of the villa is the living room with a fireplace, also one of Wright's favorite element of composition. Wright was also assisted in this project by architect Arata Endo. Once Wright's project entered the final stages of its

In 1999-2001, there were broad-scaled restoration works in the School; thanks to them, the unique architecture by Wright was preserved. 
implementation, Endo filled the Yodokō Guest House with decorative details. He also added three traditional Japanese-style rooms with tatami flooring and fusuma sliding dividers. The Yodokō Guest House was the first Taishō period building in Japan to be designated an important cultural property ${ }^{5}$. In 1989, it was opened for public visits.

Arata Endo's role in realizing the Wright's projects has been enormous. He admired Wright's organic architecture and tried to combine it with traditional Japanese architecture. He looked for opportunities, or rather artistic techniques, to create a tradition of Japanese organic architecture.

\section{F.L. WRIGHT'S INFLUENCE AT THE ARCHITECTURE OF JAPAN}

Working in Japan, Wright made a significant influence on Japanese architects. Local architectural assistants were fascinated with Wright's ideas of organic architecture; they were able to see and appreciate them in practice, and subsequently translate them into their work. Over time, architects of that generation, who had the opportunity to learn from Wright directly, also found their students and followers. Since then, the style of Frank Lloyd Wright has been traced in Japanese architecture - created both half a century ago and contemporary.

Wright's ideas can be traced back to architects such as Katsuo Seima, Kengo Kuma, and Takaharu Tetsuka. Like Wright himself, they are characterized with their attention to the placement of an object in space, taking into account the influence of climate and environment, using of innovative construction methods and technologies, as well as a special view of the organization of the space of an architectural structure.

From 1917 till 1922, young Japanese architects worked closely with Wright during the construction of the 'Imperial Hotel'. From that first generation of his direct assistants, four architects have experienced tremendous influence from Wright, which is reflected in their work - those are Antonin, Arata Endo, Kameki Tsutiura, and Yoshiya Tanoue. Those architects not only changed the image of contemporary Japan of their days with new buildings, but also raised the next generation of architects, who in turn passed on their skills to the next one.

Thus, Wright and several 'generations' of Japanese architects, who in their work were the successors of the philosophy of organic architecture, literally represented the perfect fusion of modern Western and traditional Japanese culture. Following the development of their work, you can see the dynamics of the direct and

\footnotetext{
Получение Yodokō Guest House статуса важной культурной ценности произошло в 1974 г.
}

indirect influence of the style of Frank Lloyd Wright, clarifying this organic line of development of Japanese architecture.

Arata Endo has been one of Wright's top assistants in Japan for many years. He selected draftsmen to work on the projects; he himself took part in the design, and also supervised the construction. In 1920s, Endo designed a country house for Kenzi Kondo, taking as a starting point the work by his teacher, F.L. Wright. Villa Kondo ("Fig. 4") was built in 1925. The house was built in the L-shape with a large pond in the northeastern part of the site. Endo combined architecture and nature, revealing all the advantages and beauty of the site allocated to him for construction. Following Wright's example, Endo also designed all furniture and lighting fixtures for that house. The architect envisioned two types of premises in the villa: European style on the ground floor and traditional Japanese style on the first floor.

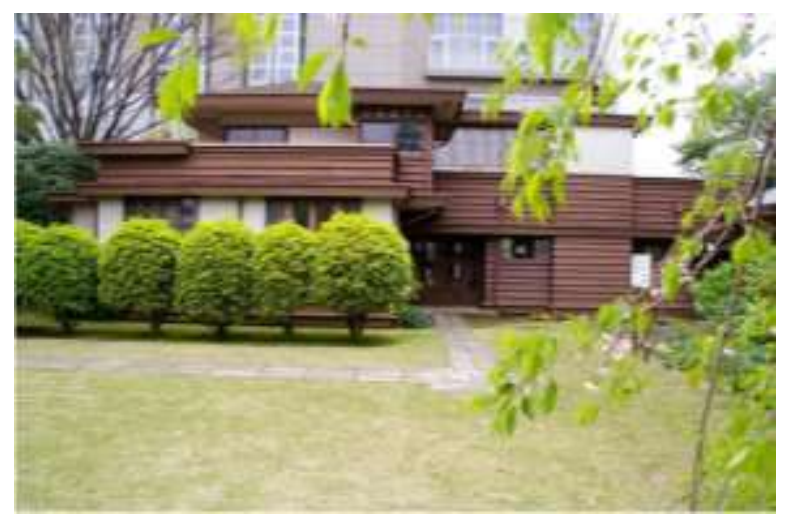

Fig. 4. A. Endo. Villa Kondo, 1925.

Yoshiya Tanoue, also a student of Wright, continued to work with Arata Endo on the construction of the 'Imperial Hotel' after the departure of the American architect. But later he decided to move north; and, in 1924, he opened his own architectural office in Sapporo. His early works largely demonstrate the influence of Wright's architecture: in the geometry of buildings, their horizontal orientation, the shape of the roof, and the use of geometric patterns of windows. In 1930s, Tanoue began to develop his style of the 'northern Japanese architecture'. He created many building designs, taking into account the climatic features of snowy Hokkaido; and now he is considered the founder of modern architecture in the northern region of Japan.

\section{CONTEMPORARY ARCHITECTURE OF JAPAN FOLLOWING THE ORGANIC PRINCIPLES}

Organic principles can be traced back to contemporary Japanese architecture. In this case, it is impossible to speak about Wright's influence only. But 
that organic path of development of Japanese architecture was shaped and began to gain popularity in Japan thanks to Wright and his students. And it developed and retained its relevance to this day, thanks to the special attitude towards nature that has existed in Japanese culture since ancient times. The traditional attitude of the Japanese towards nature has not changed fundamentally until today. In Japan, the concept of culture has never been seen as the antithesis of nature; the main peculiarity of Japanese culture is that it is a culture following nature and imitating it.
The Central Park Grin Grin, built by T. Ito (20032005, "Fig. 5"), is a real architectural masterpiece, with an area of 400 hectares, located on an artificial island. The structures, made of high-strength concrete and glass, have intricate undulating shapes that arose from the combination of a bold architectural solution with the poetics of nature. The interconnected structures are mutually over-flowing spaces, where visitors can climb to the roof and walk along it using various paths and passages.

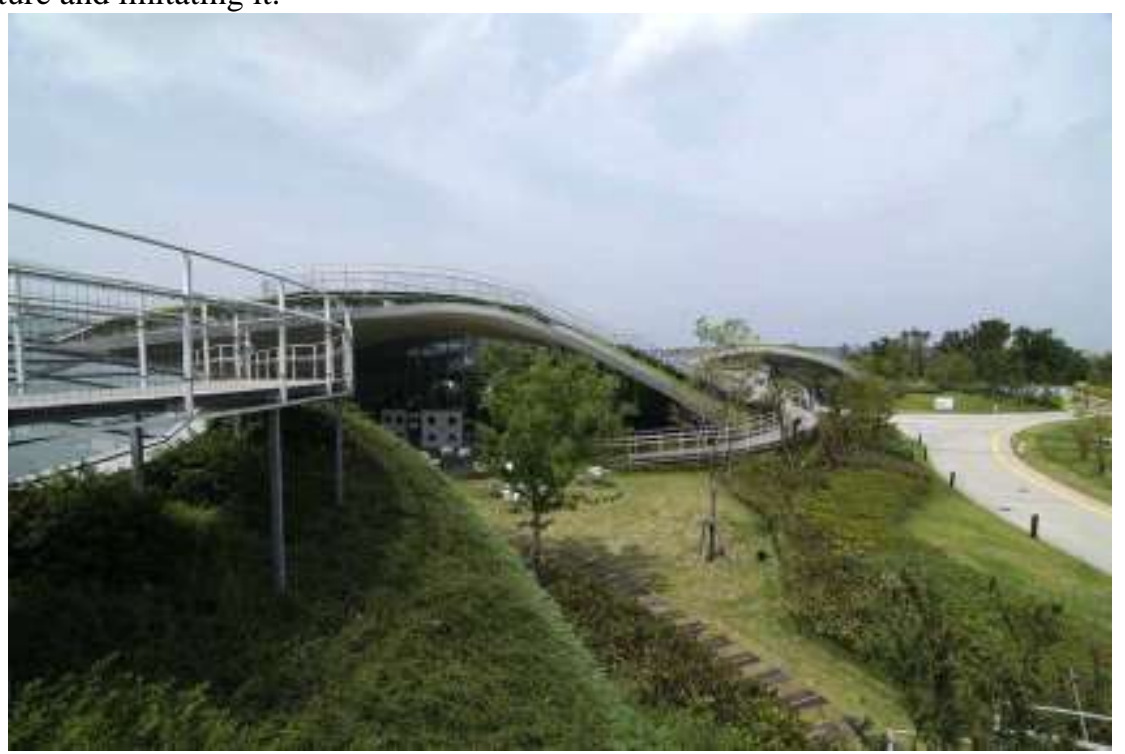

Fig. 5. T. Ito. The Central Park Grin Grin, 2005.

Since the principles of organic coexistence with nature are fundamental and intrinsic for Japanese architecture, we can safely say that it is on them, consciously or unconsciously, that the masters of Japan rely, embedding their works into the logic of the continuous and consistent development of national architecture, thereby realizing the connection between the past of their culture and its future.

Gardens, placed on the roofs or facades of modern buildings, are designed to compensate for the shrinking parks and other green zones and recreational spaces in cities. The ACROS Fukuoka project ("Fig. 6", architectural bureau Takenaka Corporation, architect Emilio Ambasz) envisaged an area of the roof garden almost twice larger than the area of the base of the building itself. This green rooftop oasis is one of a kind. Its concept is a unique combination of urbanized and parkland spaces. The north side of the 18-story building, facing the most prestigious street in the financial district of Fukuoka, features an elegant city façade made of metal and glass. The southern façade is almost completely surrounded with green spaces. It contains 15 stepped terraces, through which you can climb the green cascade to the very top. On each tier of the green terrace, gardens are created for meditation, relaxation, and simply rest from the bustle of the city. The upper terrace serves as a large belvedere, offering incomparable views of the bay and the surrounding mountains. To dampen the noises of the city's business districts as much as possible, waterfalls and pools have been created on the terraces. The pools are located directly above the central glass atrium of the building; as a result, soft diffused light penetrates the interior through the glazed tower separating the pools. In total, about 50 thousand plants are planted on the ledges of this makeshift pyramid-park, occupying an area of 5400 $\mathrm{m}^{2}$. 


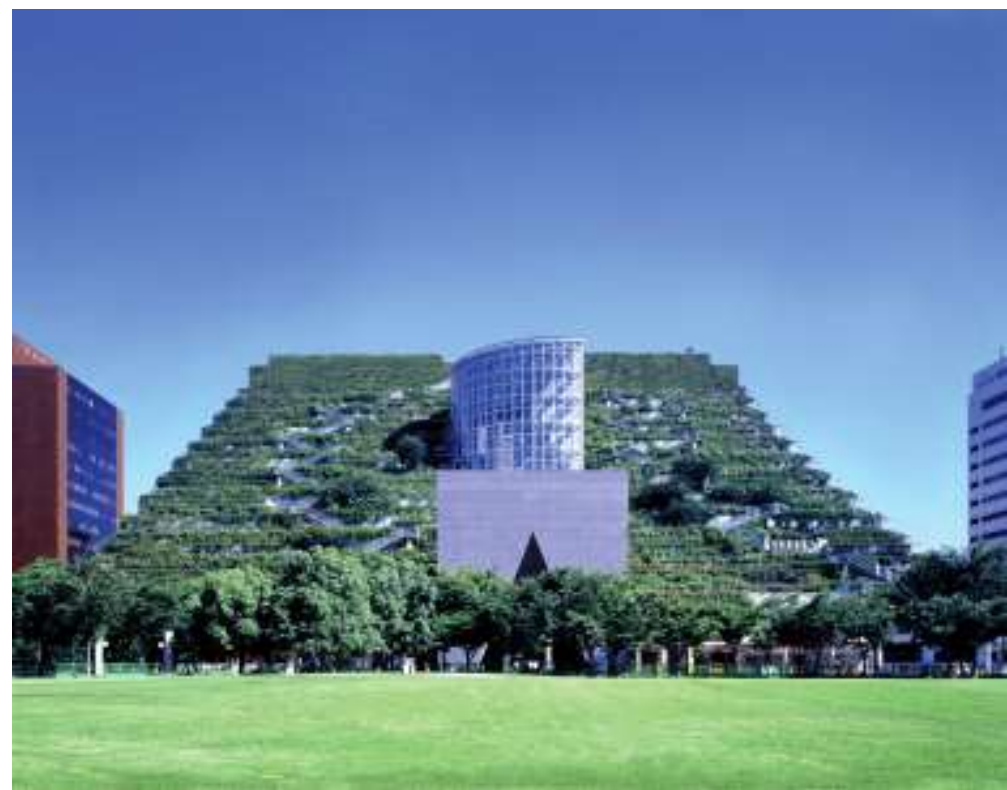

Fig. 6. E. Ambasz. ACROS Fukuoka, 1995.

Beneath the fifteen park terraces, there is over one million square meters of multifunctional space containing an exhibition hall, a museum, a 2,000-seat theater, conference rooms, halls and city administration offices, as well as retail space and offices. A roof garden helps to prevent overheating of the building and to maintain a moderate indoor temperature. This makes the working environment in this building more comfortable. The roof captures rainwater, supporting the life of plants, insects, and birds. The ACROS Fukuoka project with terraces, waterfalls, swimming pools, and a huge number of plants has realized the idea of a 'green' oasis in the center of a big city. The created structure allows a large urban structure to exist in symbiosis with the invaluable resource of open public space.

Toyo Ito's architecture does not recognize right angles and strict geometric shapes. The master contrasts them with the curvature and streamliness of his buildings. One of Ito's significant creations was the building of the municipal crematorium 'Meiso no Mori' (2006, "Fig. 7") in the Japanese city of Kakamigahara. That work by Toyo Ito has become the quintessence of the image of peace and quiet. The name of the snowwhite building, built of concrete and glass, means a 'Forest of Meditation'. The place for the crematorium was set aside on the shore of a small lake. Building helps to evoke feelings of peace and tranquility.

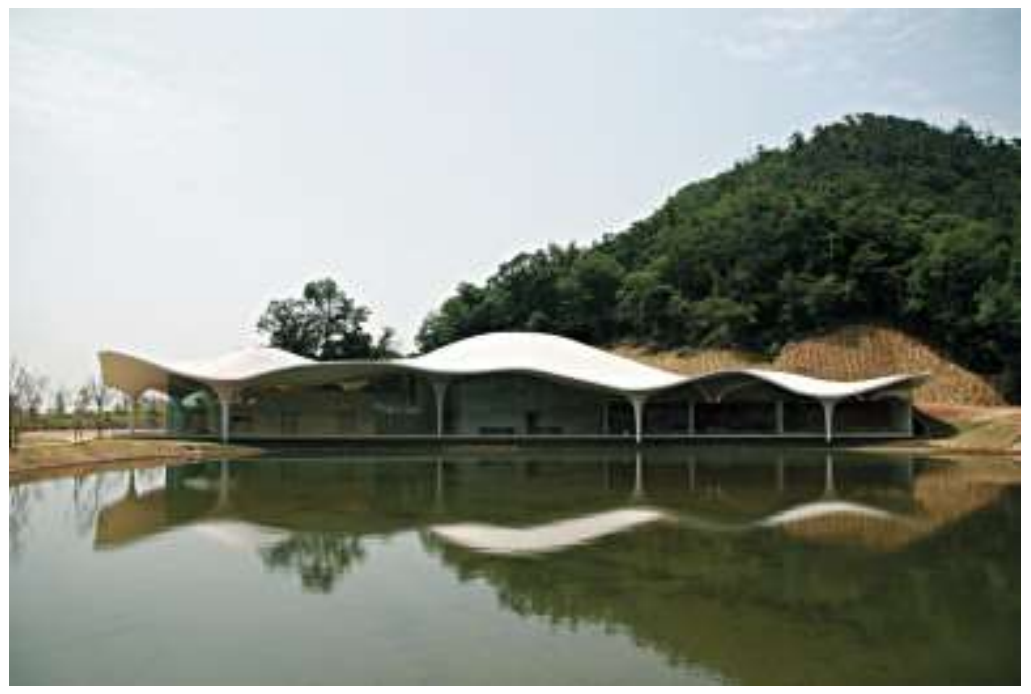

Fig. 7. T.Ito. 'Meiso no Mori', Kakamigahara, 2006. 
The new 'Meiso no Mori' was intended to replace the dilapidated crematorium, while decorating the adjoining cemetery. Inspired by the sight of gently floating clouds, Ito, when creating the project, decided to minimize the feeling of materiality of the building. The freely curved reinforced concrete sink that covers the building rests on twelve thin columns, but it seems floating above the ground. The shape of the roof was calculated according to an algorithm that sets the optimal structural solution taken by Ito likens through his structural analysis of plant evolution. Here, as in nature, the incredibly complex process of evolutionary cycles leads to surprisingly simple results. The canopy of the original covering soars up and down, as if repeating the outline of the hills at the foot of which it is located. An amazing effect is achieved in winter, when everything is covered with snow and the embossed white coating of the building is reflected in the smooth surface of the lake, just like the snow-white tops of the surrounding hills. The building seems to dissolve in the winter landscape, delicately declaring its functions.

\section{CONCLUSION}

In our opinion, these examples eloquently present the basic principles on which Japanese architects integrate their works into the logic of the development of national architecture, making a connection between the past of their culture and its future.

Almost 100 years after the first project implemented by F.L. Wright in Japan, the influence of the architect can be found in the works of his students and their followers. His artistic legacy, still relevant today, continues the dialogue between traditional Japanese architecture and contemporary organic architecture.

\section{References}

[1] Kevin Nute. Frank Lloyd Wright and the 'Organic' Nature of Japanese Architecture. In: Conference Paper, - Conference: AIJ Hokkaido, Annual Meeting, At Sapporo, Japan, September $1996 . \quad$ Режим доступа: https://www.researchgate.net/publication/324606541_Frank_L1 oyd_Wright_and_the_'Organic'_Nature_of_Japanese_Architect ure

[2] F.L. Wright: An Autobiography. - London, 1938, p.196.

[3] N.A. Konovalova. Contemporary architecture of Japan: tradition of the space perception. - Moscow, St. Petersburg: NestorHistory, 2017 [in Russian].

[4] Kevin Nute. Frank Lloyd Wright and Japan: The Role of Traditional Japanese Art and Architecture in the Work of Frank Lloyd Wright, - Van Nostrand Reinhold, 1994.

[5] D. Hoffmann. Frank Lloyd Wright: Architecture and Nature. New York: Dover Publications, 1986.

[6] C. Bolon, R. Nelson, and L. Seidel, ads. The Nature of Frank Lloyd Wright. Chicago and London: University of Chicago Press, 1988.
[7] N. Getashvili. Wright. - Series "The Great architects", Moscow, 2015 [in Russian].

[8] Cary James. Frank Lloyd Wright's Imperial Hotel (Dover Books on Architecture), - Dover Publications, N.Y., 1988.

[9] Storrer, William Allin. The Frank Lloyd Wright Companion. University of Chicago Press, 2006, P.212. 